Jurnal Scripta Teologi dan Pelayanan Kontekstual
ISSN
ISSN
Http://ejournal.stte.ac.id
Vol.4, No.1, pp. 1-15, 2019
STTE

\title{
Konsep Kesatuan Yesus dan Allah Bapa Dalam Injil Yohanes 17:22 Untuk Menghadapi Doktrin Subordinansi Tritunggal Saksi Yehuwa
}

\author{
Yanjumseby Y. Manafe \\ ${ }^{1}$ STT Ebenhaezer Tanjung Enim, manafeseby2@gmail.com \\ ${ }^{2}$ STT EbenhaezerTanjung Enim, yennyanitapattinam1980@gmail.com
}

\section{INFO ARTIKEL}

Sejarah Artikel:

Diterima : 04 Mei 2019

Direvisi : 10 Mei 2019

Disetujui: 16 Mei 2019

Dipublikasi: $28 \mathrm{Mei}$

2019

Kata Kunci:

Konsep, Kesatuan,

Subordinansi,

Tritunggal, Yehuwa.

Keywords:

keyword one, keyword two, keyword three.

\section{ABSTRAK}

Doktrin Trinitas atau doktrin Allah Tritunggal adalah pengajaran tentang Allah yang menyatakan diri-Nya dalam tiga pribadi, yaitu Allah Bapa, Allah Anak (Yesus Kristus), dan Allah Roh Kudus yang ketiganya adalah esa. Di satu sisi, doktrin tersebut merupakan doktrin yang sangat penting dan unik dalam kekristenan. Dikatakan penting karena doktrin ini berbicara tentang Allah Tritunggal yang menjadi pusat pujian, penyembahan dan pelayanan orang percaya. Dikatakan unik karena doktrin tersebut tidak terdapat dalam agama manapun di dunia ini. Namun, di sisi lain, doktrin tersebut merupakan doktrin yang sulit dipahami dan diterima oleh akal manusia bahkan menjadi bahan perdebatan yang hebat di berbagai tempat, masa dan kalangan manusia. Dengan studi eksegetis Yohanes 17: 22 sebagai dasar evaluasi kritis terhadap doktrin subordinasi Tritunggal dalam theologia Saksi Yehuwa, maka dapat diketahui bahwa doktrin subordinasi Tritunggal dalam theologia Saksi Yehuwa adalah doktrin yang menyimpang dari kebenaran Alkitab.

\footnotetext{
ABSTRACT

The doctrine of the Trinity or the doctrine of the Triune God is the teaching of God revealing Himself in three persons, namely God the Father, God the Son (Jesus Christ), and God the Holy Spirit of which all three are one. On the one hand, the doctrine is a doctrine that is very important and unique in Christianity. It is said to be important because this doctrine speaks of the triune God who is the center of the worship, worship and service of believers. Said to be unique because the doctrine does not exist in any religion in this world. However, on the other hand, the doctrine is a doctrine that is difficult to understand and accepted by human reason and even becomes a matter of great debate in various places, times and circles of humans. With the exegetical study of John 17: 22 as the basis for a critical evaluation of the doctrine of the subordination of the Trinity in the theology of Jehovah's Witnesses, it can be seen that the doctrine of the subordination of the Trinity in the theology of Jehovah's Witnesses is a doctrine that deviates from Bible truth.
} 


\section{Pendahuluan}

Allah yang dipuji, disembah dan dilayani oleh orang Kristen adalah Allah Tritunggal. Dalam theologia Kristen, Allah Tritunggal berarti tiga Pribadi di dalam satu Allah, atau di dalam satu esensi diri Allah, ada tiga Pribadi. Tiga Pribadi Allah yang dimaksud adalah Pribadi Allah Bapa, Allah Anak dan Allah Roh Kudus, yang ketiganya adalah satu. Berkaitan dengan pernyataan ini, dalam bukunya "Allah Tritunggal", Stephen Tong menulis bahwa: "Allah yang benar adalah Allah yang tidak terbatas, Allah yang melampaui segala sesuatu, Allah yang Esa, Allah yang tidak ada bandingnya, dan Allah yang menyatakan diri sebagai Allah Tritunggal."

R. C. Sproul menjelaskan bahwa Allah Tritunggal tidak sama dengan triteisme yang menyatakan ada tiga keberadaan yang tiga-tiganya adalah allah. Selanjutnya, ia menjelaskan bahwa kata "Tritunggal" dipergunakan sebagai usaha untuk menjelaskan kepenuhan dari Allah, baik dalam hal keesaan-Nya maupun dalam hal keragaman-Nya. Dengan demikian, kepercayaan orang Kristen kepada Allah Tritunggal bukanlah suatu bentuk kepercayaan kepada banyak Allah (politeisme).

Dalam theologia Kristen, pengajaran tentang Allah Tritunggal disebut doktrin Trinitas atau doktrin Allah Tritunggal. Secara terminologi istilah "Tritunggal" atau "Trinitas" tidak muncul di dalam Alkitab. Walaupun demikan, Stephen Tong berpendapat bahwa: "Yang tidak muncul di dalam Alkitab secara istilah bukan berarti bukan konsep Alkitab." Jadi, konsep Trinitas adalah konsep yang diajarkan di dalam Alkitab, baik Perjanjian Lama maupun Perjanjian Baru.

Oleh karena konsep Trinitas adalah konsep yang alkitabiah, maka pengajaran tentang Allah Tritunggal merupakan pengajaran yang sangat penting. Menurut Cornelius Van Til, "doktrin Trinitas bukanlah sebuah doktrin yang spekulatif yang hanya memiliki signifikansi yang kecil." Lebih jauh, Stevri Indra Lumintang menulis bahwa: "Doktrin Trinitas adalah esensi theologia Kristen dan fondasi dari semua rancang bangun seluruh theologia Kristen."

Dengan demikian, doktrin Trinitas merupakan keunikan kekristenan dan tidak terdapat dalam theologia agama lain. Dalam bukunya "Teologi Sistematika", Henry C. Thiessen menjelaskan bahwa doktrin Trinitas bukanlah suatu konsep yang lahir dari pemikiran manusia yang terbatas, tetapi suatu kebenaran yang dapat diketahui melalui penyataan atau wahyu Allah di dalam Alkitab. Karena itu, hanya setiap orang yang sungguh-sungguh percaya bahwa Alkitab adalah firman Allah yang dapat memahami dan menerima doktrin Allah Tritunggal.

Walaupun doktrin Trinitas merupakan doktrin yang sangat penting dan unik dalam kekristenan, namun doktrin ini juga merupakan doktrin yang sulit untuk dipahami dan diterima oleh akal manusia. Sepanjang sejarah kekristenan, doktrin Trinitas telah menjadi doktrin yang banyak diperdebatkan oleh banyak pihak.

Yang sering menjadi perdebatan dari doktrin ini adalah kesetaraan hakikat atau natur Yesus dengan Allah Bapa dan Roh Kudus, sehingga hal ini mengakibatkan penolakan terhadap doktrin Trinitas.

Ide penolakan terhadap doktrin Trinitas sebenarnya telah dicetuskan oleh Arius (sekitar 250-336 M), seorang penatua yang anti Trinitarian dari Alexandria. Dalam bukunya "Teologi Dasar 1", Charles H. Ryrie menuliskan ide Arius tersebut:

Arius (1.k th. 250-336), penatua yang anti trinitarian dari Alexandria, membedakan Allah yang kekal yang esa dari Anak yang diperanakkan oleh Bapa dan yang oleh karena itu memiliki permulaan. Ia juga mengajar bahwa Roh Kudus adalah yang pertama diciptakan oleh Anak, karena segala sesuatu dijadikan oleh Anak. Ia menemukan dukungan Kitab Suci bagi pendapatnya dalam nas-nas yang seolah-olah menggambarkan Anak sebagai lebih rendah dari Bapa (Mat. 28: 18; Mrk. 13: 32; 1 Kor. 15: 28). 
Dengan demikian, Arius menyatakan bahwa Yesus lebih rendah daripada Allah Bapa. Demikian juga, Roh Kudus lebih rendah daripada Allah Bapa dan Yesus. Dengan kata lain, Yesus dan Roh Kudus bukan Allah.

Ide Arius tersebut merupakan ancaman besar pertama yang menyerang pandangan gereja mengenai ke-allahan Yesus. Ketika Sidang Konsili di Nicea tahun 325 M dan juga beberapa konsili setelahnya, ide Arius tersebut sudah dinyatakan sebagai ajaran yang salah dengan tuduhan mengajarkan sebuah pandangan yang heterodoks tentang hubungan antara Yesus dengan Allah Bapa. Sekalipun demikian, ide Arius tersebut masih tetap bertahan dalam berbagai bentuk hingga dewasa ini.

Dewasa ini, salah satu aliran dalam kekristenan yang tetap berpegang dan meneruskan ide Arius secara agresif adalah Saksi Yehuwa. Mereka menolak kesetaraan hakikat atau natur Yesus dengan Allah Bapa dan Roh Kudus. Mereka meyakini dan mengajarkan bahwa Yesus lebih rendah daripada Allah Bapa, dan Roh Kudus lebih rendah daripada Allah Bapa dan Yesus. Keyakinan dan pengajaran ini dikenal sebagai doktrin subordinasi Tritunggal atau subordinasionisme.

Dalam bukunya "Keunikan Theologia Kristen di Tengah Kepalsuan", Stevri Indra Lumintang menuliskan keyakinan dan ajaran Saksi Yehuwa tentang Allah Tritunggal:

Keyakinan dan ajaran mereka mengenai Allah Tritunggal, bahwa Allah Bapa dan Putra Allah adalah dua pribadi, sedangkan Roh Kudus adalah berbeda secara hakiki dan terpisah satu dengan yang lainnya. Bagi mereka, Allah Bapa adalah Yehovah, Sang Pencipta dan lebih tinggi dari putra (SIL: Subordinasi), sedangkan Yesus Kristus adalah saksi dan pelayan utama dari Yehovah. Mengenai Roh Kudus, Ia bukanlah pribadi tersendiri dari Allah melainkan Kuasa, daya pengaruh dari Allah Bapa.

Paulus Daun menjelaskan bahwa Saksi Yehuwa menolak pernyataan bahwa Yesus Kristus dan Roh Kudus adalah Allah. Mereka menyatakan bahwa doktrin Allah Tritunggal tidak boleh dipercayai karena tidak berasal dari Alkitab, tetapi berasal dari setan. Dengan demikian, dapat dipahami bahwa doktrin subordinasi Tritunggal dalam theologia Saksi Yehuwa menekankan adanya perbedaan antara hakikat Yesus dengan Allah Bapa dan Roh Kudus.

Saksi Yehuwa mengajarkan doktrin subordinasi Tritunggal tidak hanya kepada para anggota saksi-saksi Yehuwa saja, tetapi juga mengajarkannya kepada orang-orang Kristen dengan sangat giat, tabah dan fanatik. Mereka biasanya datang ke rumah-rumah secara berpasangan dan membawa sejumlah buku untuk dijual atau dibagikan secara cuma-cuma dengan sampul buku dan isi buku yang berwarna menarik. Hasilnya, tidak sedikit orang Kristen menjadi percaya kepada doktrin tersebut, terutama mereka yang tidak memiliki pemahaman yang mendalam tentang Alkitab.

Dalam buku "Bagaimana Menghadapi Saksi Yehuwa" yang diterbitkan oleh Badan Literatur Baptis dicatat bahwa jumlah pengikut Saksi Yehuwa mengalami pertumbuhan pesat:

Dalam waktu sepuluh tahun antara 1942-1952, keanggotaan Saksi Yehuwa berlipat ganda di Amerika Utara, lima kali lipat di Asia, tujuh kali lipat di Eropa, dan 15 kali di Amerika selatan. Pada tahun 1958 pertemuan antar bangsa dari saksi Yehuwa dihadiri oleh lebih dari seperempat juta orang. Menurut majalah Saksi Yehuwa sendiri: "Dalam masa hanya tiga tahun yang telah lewat, 1969, 1970, dan 1971, dalam 207 negeri dan pulau-pulau, 434.906 orang telah mengadakan perubahan besar dalam kehidupan mereka dengan membuat diri mereka layak menerima pahala kehidupan kekal.

Selain data di atas, menurut 2013 Yearbook of Jehovah's Witnesses, jumlah orang yang menghadiri peringatan tahunan Saksi Yehuwa terhadap kematian Kristus atau disebut 
juga Perjamuan Malam Tuhan adalah 19.013.343 orang. Hal ini membuktikan bahwa jumlah pengikut Saksi Yehuwa mengalami pertumbuhan pesat di seluruh dunia.

Salah satu penyebab pertumbuhan yang pesat tersebut adalah karena doktrin yang menarik dan lebih sederhana dari pada ajaran-ajaran Kristen yang biasanya, misalnya mereka mengajarkan penolakan terhadap doktrin Tritunggal dan keilahian Yesus. Pengajaran mereka tersebut disebabkan oleh doktrin subordinasi Tritunggal dalam theologia mereka.

Penerimaan terhadap doktrin subordinasi Tritunggal tersebut mengakibatkan pemahaman yang salah tentang hakikat Yesus yang sesungguhnya. Dengan kata lain, penerimaan doktrin subordinasi Tritunggal mengakibatkan pemahaman yang salah tentang kristologi. Pemahaman kristologi yang salah akan menghasilkan theologia yang salah. Sebaliknya, pemahaman kristologi yang benar akan menghasilkan theologia yang benar karena kristologi adalah poros theologia. Dengan demikian, orang yang percaya pada doktrin subordinasi Tritunggal tidak memiliki pemahaman yang utuh tentang Allah Tritunggal yang menjadi pusat ibadah, penyembahan dan pelayanan orang percaya.

Doktrin subordinasi Tritunggal dalam theologia saksi Yehuwa adalah suatu problematika theologis yang sangat serius dan menjadi racun bagi doktrin Kristen yang alkitabiah. Dengan semakin banyaknya orang yang percaya kepada doktrin subordinasi Tritunggal tersebut, maka semakin banyak orang yang menyangkal kepercayaannya kepada Allah Tritunggal. Akibatnya, semakin banyak orang yang tersesat dan semakin banyak pula penyesat. Oleh karena itu, doktrin subordinasi Tritunggal dalam theologia Saksi Yehuwa harus dievaluasi secara kritis melalui kebenaran firman Allah karena hanya firman Allahlah yang menjadi satu-satunya standar atau tolok ukur terhadap kebenaran suatu doktrin atau theologia seperti yang terdapat dalam prinsip reformasi "sola scriptura."

Oleh karena itu, untuk menjawab problematika theologis dari doktrin subordinasi Tritunggal tersebut, maka penulis tergerak untuk melakukan studi eksegetis terhadap perkataan Tuhan Yesus dalam Injil Yohanes 17: 22, yaitu: "Dan Aku telah memberikan kepada mereka kemuliaan, yang Engkau berikan kepada-Ku, supaya mereka menjadi satu, sama seperti Kita adalah satu." Dengan memahami perkataan Tuhan Yesus dalam Injil Yohanes 17: 22, secara khusus konsep kesatuan Yesus dan Allah Bapa, diharapkan orang percaya dapat memiliki pengetahuan yang mendalam tentang hakikat Yesus yang sesungguhnya dan dapat memperlengkapi diri serta dapat mengambil sikap yang benar dalam menghadapi doktrin subordinasi Tritunggal dalam theologia Saksi Yehuwa.

\section{Metode Penelitian}

Penelitian ini adalah penelitian kualitatif dengan pendekatan grammatical analysis. grammatical analysis adalah "the first stage of determining the inner cohesion of the text is to analyze the relationships entween the individual units or terms in the next".(Osbone;1991:19). Paradigma yang digunakan adalah paradigma naturalistik, yang pada hakikatnya merupakan suatu upaya untuk menemukan kebenaran atau untuk lebih membenarkan kebenaran. Kebenaran yang dimaksud adalah Kebenaran konsep Integritas yang tertulis dalam Injil Matius 5: 17-20.

Teknik pengumpulan data dalam penelitian ini dilakukan dengan wawancara, pengamatan atau partisipasi langsung dan penelaahan dokumen. Dalam wawancara ini, peneliti menggunakan pedoman secara tertulis yang telah dipersiapkan sebelumnya yang berisi sejumlah pertanyaan yang akan digunakan. Pertanyaan-pertanyaan yang diajukan dalam proses wawancara berpijak dari kajian literatur yang dimaksudkan untuk mengetahui bagaimana konsep integritas dalam Matius 5:17-20 
Analisis data yang digunakan dalam penelitian ini mengikuti langkah-langkah grammatical analysis. Langkah penafsiran yang akan ditempuh sebagai berikut: 1). Teks Matius 5:17-20 akan ditafsirkan ayat demi ayat; 2). Penafsiran tiap tiap ayat akan mengerucut kepada kalimat demi kalimat dan frasa demi frasa; 3). Penelusuran terhadap meaning dari setiap frasa akan sangat terlihat hal ini dengan Tujuan supaya dapat melihat atau mendapat sense dari meaning yang dimaksud berkenaan dengan konsep Integritas

\section{Hasil Dan Pembahasan}

Konsep Kesatuan Yesus Dan Allah Bapa Dalam Injil Yohanes 17: 22

Pada bagian ini, penulis akan membahas tentang studi eksegetis Yohanes 17: 22 untuk memahami konsep kesatuan Yesus dan Allah Bapa. Oleh karena itu, penulis memulai pembahasan dengan memaparkan pengenalan terhadap Injil Yohanes, dilanjutkan dengan makna theologis Yohanes 17: 22 dan diakhiri dengan suatu kesimpulan berdasarkan pembahasan tersebut.

\section{Latar Belakang Penulisan Injil Yohanes}

Penulisan Injil Yohanes dilatarbelakangi oleh konflik yang terjadi di antara orangorang Yahudi dengan orang-orang Kristen yang berlatar belakang Yahudi dan juga kecurigaan penguasa Roma terhadap orang-orang di luar Yahudi yang tidak menyembah kaisar. Setelah perang pada tahun 70 M banyak orang Yahudi di dalam kekaisaran Roma ingin menjauhkan diri dari sekte yang menekankan pengajaran tentang Mesias, kerajaan dan nubuatan. Karena itu, orang-orang Kristen yang berlatar belakang Yahudi tidak disambut dengan baik oleh penguasa-penguasa sinagoge, bahkan keyahudian mereka diragukan karena mereka percaya kepada Yesus sebagai Mesias dan Pembawa Kerajaan (kingdom-bringer). Karena itu, Yohanes menulis Injil ini untuk meyakinkan para pembaca bahwa iman di dalam Yesus adalah sesungguhnya ajaran Kitab Suci Yahudi, dan bahwa orang-orang yang menentang merekalah yang salah memahami kitab Suci.

\section{Tujuan Penulisan Injil Yohanes}

Di dalam Yohanes 20: 31 dicatat: "Tetapi semua yang tercantum di sini telah dicatat, supaya kamu percaya, bahwa Yesuslah Mesias, Anak Allah dan supaya kamu oleh imanmu memperoleh hidup dalam nama-Nya." Jadi, tujuan utama penulisan Injil Yohanes adalah supaya pembaca percaya bahwa Yesus ialah Mesias dan anak Allah, sehingga kepercayaan mereka kepada Yesus membawa mereka ke dalam pengalaman hidup yang kekal.

\section{Waktu dan Tempat Penulisan}

Kebanyakan penafsir setuju bahwa Injil Yohanes ditulis menjelang akhir abad pertama. Menurut tradisi gereja, Yohanes sudah selesai menulis Injil sebelum ia meninggal. Berdasarkan tradisi tersebut, diperkirakan waktu penulisan Injil Yohanes adalah antara tahun 90 dan 100 M. Mengenai tempat penulisan Injil Yohanes, keterangan yang kuat adalah tulisan Irenius yang dikutip oleh D. A. Carson dalam bukunya "The Gospel According to John": "As for the Fourth Gospel itself, he wrote: 'John the disciple of the Lord, who leaned back on his breast, published the Gospel while he was resident at Ephesus in Asia." Jadi, Yohanes menulis dan menerbitkan Injil Yohanes ketika ia tinggal di Efesus. 


\section{Eksegese Yohanes 17: 22}

Eksegese berarti membaca, menggali dan mengeluarkan atau membawa keluar arti dari suatu teks Alkitab. Oleh karena itu, untuk memahami arti teks Yohanes 17: 22, maka penulis akan menguraikan latar belakang teks, analisa konteks, analisa struktur, dan analisa kata dari Yohanes 17: 22.

\section{Latar Belakang Teks Yohanes 17: 22}

Kesatuan Bapa dan Anak menjadi pola kesatuan bagi orang-orang percaya. Orangorang Yahudi mengenal bahwa Allah adalah satu. Pengenalan ini penting untuk memelihara persaudaraan mereka di antara bangsa-bangsa atau di tengah-tengah dunia yang memusuhi mereka. Kesatuan ini juga ditujukan kepada pembaca atau penerima Injil Yohanes, yang sedang mengalami perlawanan dari penguasa-penguasa sinagoge. Sepertinya penekanan kesatuan ini juga ditujukan untuk kesatuan suku bangsa dan budaya yang sering menjadi pemicu konflik di antara orang-orang Yahudi yang berdiaspora dengan orang-orang non-Yahudi. Dengan demikian, dapat dipahami bahwa Yohanes ingin menekankan kepada orang-orang Yahudi yang tinggal di luar Palestina atau berdiaspora bahwa kesatuan Yesus dengan Allah Bapa merupakan dasar kesatuan semua orang percaya.

\section{Analisa Konteks Yohanes 17: 22}

Untuk memahami suatu teks Alkitab dengan baik, maka perlu memperhatikan konteks ayat tersebut. Oleh karena itu, penulis akan memaparkan konteks dekat dan konteks jauh dari Yohanes 17: 22.

\section{Konteks Dekat}

Konteks dekat dari teks Yohanes 17: 22 adalah ayat 20, 21 dan 23. Ayat 20 merupakan doa Tuhan Yesus bagi semua orang percaya. Ayat 21 merupakan kerinduan Tuhan Yesus supaya semua orang percaya menjadi satu sehingga membuat dunia tahu bahwa Yesus Kristus diutus oleh Allah Bapa. Pada ayat 23, Tuhan Yesus kembali menyatakan kerinduan dan tujuan yang sama seperti dalam ayat 21. Dasar kesatuan semua orang percaya adalah kesatuan Yesus dengan Allah Bapa, di mana Allah Bapa di dalam Yesus dan Yesus di dalam Allah Bapa. Melalui ayat-ayat ini dapat dipahami bahwa orang percaya dapat hidup dengan benar hanya karena karya Tuhan Yesus.

\section{Konteks Jauh}

Konteks jauh dari teks Yohanes 17: 22 adalah Yohanes 17: 1-5, 6-10, 11-19, 24-26. Ayat 1-5 merupakan doa Tuhan Yesus agar Bapa mempermuliakan-Nya. Tujuan doa Yesus tersebut adalah supaya Yesus mempermuliakan Bapa. Ayat-ayat ini menyatakan bahwa ada kesatuan kemuliaan Yesus dan Allah Bapa.

Ayat 6-11 merupakan doa Yesus bagi murid-murid-Nya. Allah Bapa telah memberikan mereka kepada Yesus untuk menjadi milik Yesus dan di saat yang sama mereka adalah milik Allah Bapa. Murid-murid tersebut tahu dan percaya bahwa Yesus datang dan diutus oleh Allah Bapa. Ayat 12-19 merupakan doa Yesus bagi murid-murid yang tinggal di dunia. Yesus tidak lama lagi bersama-sama dengan murid-murid-Nya di dunia karena Ia akan kembali kepada Allah Bapa di sorga. Oleh karena itu, Yesus meminta kepada Allah Bapa agar melindungi murid-murid-Nya yang masih tinggal di dunia dan menguduskan mereka dalam kebenaran. Ayat 24-26 merupakan kerinduan Yesus agar semua orang percaya melihat kemuliaan Allah. Yesus mau supaya di mana pun Dia berada, mereka bersama-sama dengan Dia. Yesus telah memberitahukan nama Allah Bapa 
kepada mereka dan terus diberitahukan supaya kasih Allah dan Yesus sendiri ada di dalam mereka.

Berdasarkan konteks jauh yang telah dipaparkan di atas, maka dapat dipahami bahwa Yesus sangat mengasihi semua orang percaya dan merindukan agar mereka tetap bersatu. Kesatuan ini diperlukan karena mereka masih tinggal di dunia yang membenci mereka.

\section{Analisa Kata Yohanes 17: 22}

Penulis akan melakukan analisa kata-kata yang terdapat dalam teks asli (bahasa Yunani) Yohanes 17: 22 dan memaparkan arti dari kata-kata tersebut.

\section{"Dan Aku telah memberikan"}

Kata "Kai." (kai) merupakan conjuction (kata penghubung) yang memiliki dua pengertian dasar, yaitu pertama, sebagai copulative (kata sambung) yang menggabungkan kata-kata atau kalimat-kalimat, diterjemahkan sebagai "dan". Kedua, sebagai penanda atau penegasan yang ditambahkan pada sesuatu hal yang telah disampaikan, diterjemahkan sebagai "juga, bahkan." Berdasarkan pengertian kata "Kai." (kai) tersebut, maka pernyataan Yesus dalam ayat 22 ini memiliki kesinambungan dan hubungan yang sangat erat dengan pernyataan-Nya dalam ayat-ayat sebelumnya, secara khusus ayat 20 dan 21 di mana Yesus berdoa bagi kesatuan semua orang percaya. Ayat 22 menegaskan karya Yesus, yaitu memberikan kemuliaan bagi semua orang percaya supaya mereka menjadi satu. Jadi, di sini jelas bahwa ada hubungan yang sangat erat antara kemuliaan yang diberikan oleh Yesus dengan kesatuan orang-orang percaya.

Kata "evgw" (ego) merupakan kata ganti orang pertama tunggal, artinya "Aku." Kata "evgw" (ego) ini mengacu pada Yesus. Dalam ayat 22 ini, kata "evgw" (ego) berlaku sebagai nominative. Artinya, Yesus merupakan subyek dari kalimat tersebut. Sebagai nominative, jika kata "evgw" (ego) bergabung dengan verb (kata kerja), maka pada umumnya pengertiannya menyatakan kesungguhan atau penekanan khusus. Dalam ayat ini, kata "evgw" (ego) bergabung dengan kata kerja "de,dwka" (dedoka) yang berasal dari kata dasar "di,dwmi" (didomi) artinya memberi.

W. E. Vine mendefinisikan kata "di,dwmi" sebagai berikut:

DIDOMI (di,dwmi)", to give, is used with various meanings according to the context; it is said, e.g. of seed yielding fruit, Mark 4: 7, 8; of giving (i.e., exercising) diligence, Luke 12: 58; of giving lots, Acts 1: 26, R.V. (A.V., "gave forth"); of rendering vengeance, 2 Thess. 1: 8; of striking of smitting Christ, John 18: 22 (lit., 'gave a blow') and 19: 3 (lit., 'they gave him blows'); of putting a ring on the hand, Luke 15: 22; of Paul's adventuring himself into a place, Acts 19: 31.

Berdasarkan definisi yang diberikan oleh Vine tersebut, maka secara sederhana kata "di,dwmi" dapat diartikan" memberikan sesuatu kepada seseorang".

Dalam ayat ini, kata "di,dwmi" (didomi) ditulis dalam bentuk verb indicative perfect active first person singular sehingga artinya adalah "Aku telah memberikan." Dengan kata lain, Yesus telah selesai dan sempurna memberikan kemuliaan. Oleh karena kata "evgw" (ego) bergabung dengan kata kerja "di,dwmi" (didomi), maka kalimat "Dan Aku telah memberikan" menekankan kesungguhan dan kesempurnaan tindakan dan kuasa Yesus dalam memberikan kemuliaan kepada semua orang percaya. Kesungguhan dan kesempurnaan yang dimaksud juga berkaitan dengan kualitas dari hasil tindakan itu. Karena itu, semua orang percaya sungguh telah menerima dan memiliki kemuliaan Allah secara sempurna melalui Yesus Kristus. 


\section{"kepada mereka"}

Kata "auvtoi/j" (autois) merupakan kata ganti orang ketiga maskulin jamak. Dalam ayat ini, kata "auvtoi/j" (autois) berlaku sebagai dative (obyek tidak langsung), artinya kepada mereka. Kata "auvtoi/j" (autois) mengacu pada semua orang yang percaya kepada Yesus. Hal ini berarti bahwa obyek dari tindakan pemberian kemuliaan yang dilakukan oleh Yesus adalah semua orang percaya di segala tempat dan zaman.

Pemahaman yang benar bahwa semua orang percaya adalah obyek atau sasaran dari tindakan yang dilakukan Yesus, yaitu memberikan kemuliaan, menegaskan bahwa semua orang percaya adalah penerima dan pemilik kemuliaan Allah. Oleh karena itu, orang percaya tidak dapat menambahkan ataupun memberi kemuliaan kepada Allah dengan cara apapun karena sumber kemuliaan orang percaya adalah dari Yesus yang adalah Allah sendiri. Dengan kata lain, kemuliaan Allah tidak dipengaruhi oleh cara, sikap dan tindakan apa pun dari manusia. Kemuliaan Allah adalah tetap dari kekal sampai kekal, tidak pernah berkurang dan tidak pernah bertambah.

\section{"kemuliaan"}

Kata "do,xan" (doxan) berasal dari kata dasar "do,xa" (doxa) yang artinya reputation (nama baik), honor (kehormatan), glory (kemuliaan). Kata "do,xa" muncul 167 kali dalam Perjanjian Baru, secara khusus dalam Injil Yohanes sebanyak 18 kali. Kata "do,xa" (doxa) merupakan sebuah kata benda umum feminim tunggal dan dalam ayat ini berlaku sebagai accusative (obyek langsung) dari kalimat "Aku telah memberikan." Artinya, yang diberikan oleh Yesus kepada semua orang percaya adalah kemuliaan.

D. A. Carson menjelaskan arti kata "glory" (kemuliaan) dalam ayat ini: "Glory commonly refers to manifestation of God's character or person in a revelatory context; Jesus has mediated the glory of God, personally to his first followers and through them to those who believe on account of their message." Penjelasan serupa dituliskan dalam buku "A Dictionary of Biblical Tradition in English Literature": "In both testaments the noun glory can often helpfully be paraphrased "manifest character," especially in Isaiah, Ezekiel, the Gospel of John, and the Pauline Epistels." Selanjutnya, William Hendrikson menuliskan bahwa:

When believers are in Christ (cf. "that they also may be in us," verse 21), then Christ is in them. This is their glory. By "the glory which thou hast given me" Jesus refers to the fact that the Father manifested himself in the Son ("thou in me" verse 21). By "I have given them" he means that he (i.e., Jesus) manifested himself in the lives of believers. To be able to say, "Christ only, always, living in us," is their glory.

Berdasarkan pengertian kata "glory" (kemuliaan) di atas, maka kemuliaan dapat diartikan sebagai manifestasi karakter Allah dalam kehidupan orang percaya. Yesus memberikan kemuliaan kepada semua orang percaya berarti Yesus memberikan karakter baru, yaitu karakter Allah bagi semua orang percaya. Hal ini terjadi karena Yesus telah tinggal dalam hidup mereka dan mereka tinggal di dalam Yesus. Inilah karakter orang yang telah memiliki hidup baru di dalam Yesus Kristus (2Kor. 5: 17).

\section{"yang Engkau telah berikan kepada-Ku”}

Kata "h]n" (hen) merupakan relative pronoun (kata ganti penghubung) yang menghubungkan kata "do,xan" (doxan) dengan "de,dwka,j" (dedokas). Kata "h]n" (hen) berasal dari kata dasar "o[j" (hos) dan ditulis dalam bentuk accusative (obyek langsung), artinya "yang". Kata "memberi" "de,dwka,j" (dedokas) berasal dari kata "di,dwmi" (didomi) . Kata ini ditulis dalam bentuk verb indicative perfect active second person singular yang artinya "Engkau telah memberikan." Second person singular (orang kedua tunggal) mengacu pada Allah Bapa yang telah memberikan kemuliaan kepada Yesus. 
Kata "moi" (moi) merupakan kata ganti orang pertama tunggal dari kata dasar "evgw" (ego), artinya "Aku" yang mengacu pada Yesus. Dalam ayat ini kata "moi" (moi) berlaku sebagai dative (obyek tidak langsung), artinya "kepada-Ku." Hal ini menyatakan bahwa obyek dari tindakan Allah adalah Yesus. Maksud bahwa Yesus sebagai obyek dari tindakan Allah dapat dipahami dengan membaca konteks jauh dari ayat 22 ini, yaitu ayat 1-5 tentang doa Tuhan Yesus agar Bapa mempermuliakan Dia.

Berkaitan dengan maksud doa Yesus kepada Bapa agar Bapa mempermuliakan-Nya (ayat 1-5), maka Leon Morris menjelaskan bahwa: "He prays for his glorification "so that the Son may glorify you" for the glory of the Father and that of the Son are one." Dengan demikian, ayat 1-5 menekankan kesatuan kemuliaan Bapa dan Yesus di mana kemuliaan Allah Bapa adalah juga kemuliaan Yesus. Jadi, tindakan Allah Bapa, yaitu memberikan kemuliaan kepada Yesus, tidak mengindikasikan bahwa Yesus lebih rendah dari pada Allah Bapa, tetapi harus dimengerti dalam hubungan kesatuan kemuliaan Yesus dengan Allah Bapa, karena kemuliaan Bapa dan kemuliaan Yesus adalah satu. Kesatuan kemuliaan ini disebabkan oleh kesatuan hakikat atau natur Yesus dengan Allah Bapa.

\section{"supaya mereka menjadi satu”}

Kata "i[na" (hina) merupakan conjuction (kata penghubung), artinya supaya. Dalam ayat 22 ini, kata "i[na" (hina) menyatakan tujuan dari tindakan Yesus. Kata "w=sin" (osin) merupakan kata ganti orang ketiga jamak dari kata dasar "eivmi," (eimi) yang artinya be (adalah atau menjadi). Kata "w=sin" (osin) ditulis dalam bentuk nominative (subyek kalimat) dan dalam bentuk verb subjunctive present active third person plural, artinya "mereka adalah" atau "mereka menjadi". Bentuk subjunctive present bermaksud menyatakan sifat kesatuan orang percaya, yaitu terus menerus. Artinya, kesatuan orang percaya bukanlah kesatuan dalam jangka waktu tertentu saja, tetapi kesatuan yang dialami secara terus menerus. Kata "e]n" (en) berasal dari kata dasar "ei-j" dan merupakan adjective (kata sifat), artinya satu.

Pada pembahasan sebelumnya telah dipaparkan bahwa penerima Injil Yohanes adalah orang-orang Yahudi yang tinggal di luar Palestina atau berdiaspora. Mereka hidup berdampingan dengan orang-orang yang berasal dari latar belakang kehidupan yang berbeda-beda, baik suku, bahasa, budaya, pendidikan, warna kulit, minat dan karakter masing-masing. Perbedaan latar belakang kehidupan ini sering kali menjadi pemicu konflik di antara mereka.

Keadaan yang dialami oleh penerima Injil Yohanes juga dialami oleh semua orang percaya di segala tempat dan zaman. Namun, dengan memiliki kemuliaan Allah, yakni manifestasi karakter Allah dalam kehidupan orang percaya, maka semua orang percaya dapat bersatu walaupun memiliki latar belakang kehidupan yang berbeda-beda. Mereka memiliki cara pandang yang benar terhadap sesama karena karakter Allah ada dalam kehidupan mereka. Jadi, tujuan Yesus memberikan kemuliaan kepada semua orang percaya adalah supaya semua orang percaya menjadi satu secara terus menerus sekalipun di antara mereka ada banyak perbedaan.

\section{"sama seperti Kita adalah satu"}

Kata "kaqw.j" (katos) merupakan adverb (kata keterangan) artinya just as (sama seperti), according to (menurut). Kata ini menyatakan comparison (perbandingan) atau degree (derajat). Dengan demikian, kata "kaqw.j" (katos) menyatakan suatu perbandingan antara pokok pikiran yang terkandung dalam kalimat sesudahnya sebagai alasan dan dasar atau pola terhadap pokok pikiran yang terkandung dalam kalimat sebelumnya. Jadi, Yesus bermaksud menerangkan dan memperbandingkan kesatuan antara Dia dengan Allah Bapa 
sebagai alasan dan dasar atau pola bagi kesatuan semua orang percaya. Dengan kata lain, karena Yesus dan Bapa adalah satu, maka semua orang percaya juga harus menjadi satu.

Kata "h 'mei/j" (hemeis) merupakan kata ganti orang pertama jamak dari kata "evgw" (ego), artinya "Kita". Dalam konteks ayat ini, kata "h 'mei/j" (hemeis) mengacu pada Allah Bapa dan Yesus. Pernyataan Yesus yang menyebut Dia dan Allah Bapa dengan istilah "Kita" menekankan suatu pernyataan theologis yang sangat mendasar dan penting untuk dipahami. Hal ini menekankan tentang hakikat atau natur Yesus yang sesungguhnya. Di dalam Alkitab, hanya Allah yang berkata kepada diri-Nya sendiri dengan menggunakan istilah "Kita" seperti yang tertulis dalam Kejadian 1: 26. Dalam Kejadian 1: 26 ini, istilah "Kita" mengacu kepada Allah Tritunggal. Tidak ada seorang pun manusia yang pernah berkata kepada Allah Bapa dengan menggunakan istilah "Kita", kecuali Yesus sendiri.

Dengan demikian, melalui kata "h 'mei/j" (hemeis), artinya "Kita" jelas bahwa hanya Yesuslah satu-satunya dalam natur-Nya sebagai manusia sejati yang berani berkata kepada Allah Bapa dengan sebutan "Kita". Hal ini merupakan suatu pernyataan yang menegaskan bahwa Yesus sendiri telah mengklaim bahwa Ia adalah Allah sejati. Ia adalah pribadi kedua dari Allah Tritunggal. Ia (Yesus), Allah Bapa dan Roh Kudus adalah satu.

Kata "e]n" (hen) dari kata dasar "ei-j" (eis), merupakan adjective (kata sifat), yang artinya satu. Dalam buku "A Greek-English Lexicon of The New Testament" dicatat bahwa kata "e]n" (hen) merupakan cardinal number, one. Pada umumnya digunakan sebagai oposisi terhadap pembagian atau penggolongan ke dalam banyak bagian, dan oposisi halhal yang bersifat etis terhadap perselisihan atau pertikaian; disatukan secara sangat dekat, baik dalam kehendak maupun dalam roh (Yoh. 10: 30; 17: 11, 21, 23). Kata "evsmen" (esmen) merupakan verb indicative present active first person plural dari kata dasar "eivmi," (eimi) yang kebanyakan berfungsi sebagai predikat, artinya "adalah", atau "menjadi." Kata ini menerangkan hakikat Yesus, Allah Bapa dan Roh Kudus, yaitu satu.

Jadi, kesatuan Yesus dengan Allah Bapa dan Roh Kudus menegaskan bahwa Allah Tritunggal tidak terbagi-bagi atau terpisah-pisah. Kesatuan ini juga menyatakan kesetaraan Yesus dengan Allah Bapa dan Roh Kudus, baik kesetaraan natur maupun kuasa. Selain itu, kesatuan ini menegaskan bahwa tidak ada yang lebih rendah atau saling bertentangan dalam masing-masing pribadi Allah Tritunggal.

\section{Makna Teologis Yohanes 17: 22}

Berdasarkan pembahasan di atas, maka penulis akan menguraikan makna teologis perkataan Tuhan Yesus dalam Yohanes 17: 22, yaitu membuktikan kesetaraan Yesus dengan Allah Bapa dan Roh Kudus, dan mengajarkan doktrin Tritunggal.

\section{Membuktikan Kesetaraan Yesus Dengan Allah Bapa dan Roh Kudus}

Pernyataan Yesus dalam Yohanes 17: 22: "Dan Aku telah memberikan kepada mereka kemuliaan yang Engkau berikan kepada-Ku, supaya mereka menjadi satu, sama seperti Kita adalah satu" menunjukkan kesetaraan Yesus dengan Allah Bapa dan Roh Kudus. Kesetaraan yang dimaksud adalah kesetaraan natur dan kuasa.

\section{Natur}

Kata "natur" berarti hakikat, esensi. Yohanes 17: 22 membuktikan bahwa Yesus memiliki natur atau hakikat yang sama dengan Allah Bapa dan Roh Kudus. Hal ini dibuktikan oleh penggunaan kata "kaqw.j" (katos) oleh Yesus, artinya "sama seperti". Di sini Yesus memperbandingkan kesatuan diri-Nya dengan Allah Bapa dan Roh Kudus, 
sebagai pola atau dasar kesatuan semua orang percaya. Selain itu, istilah "Kita" menunjukkan bahwa Yesus mengklaim diri-Nya adalah Allah (band. Kej. 1: 26).

G. Campbell Morgan menjelaskan makna kesatuan Yesus dengan Allah Bapa dan Roh Kudus sebagai berikut:

"As we are one." First of all, that is vital and essential oneness. He was one with the Father vitally and essentially. Now, He prayed that these, kept in His name, may be one in that way; having a vital relationship. Not the oneness of sentiment or intellectual opinion, but the oneness that is living. One in life, therefore one in light, and therefore one in love. He and the Father were one in essential life. He and the Father were one intellectually in all light and understanding. He and the Father were one in love. Keep them there; keep them in the name I have revealed, and manifested to them. Keep them there, that they may be one as We; one in life, one in light, one in love.

Demikian juga William Hendrikson menjelaskan hal yang serupa tentang kesatuan Yesus dengan menuliskan:

The oneness for which Christ makes request is more than an ethical unity. It is a oneness so intimate, so vital, so personal that it is patterned after, and based on, the relations which exist between the persons of Holy Trinity: it is a oneness not only of faith, hope, and love but of life itself. Together, believers constitute one Body, of which Christ is the exalted (organic and ruling) Head. Cf. Eph. 1: 22, 23; 4: 4-6.

Berdasarkan penjelasan di atas, maka kesatuan Yesus dengan Allah Bapa dan Roh Kudus mengacu pada kesatuan hidup dan natur atau hakikat. Hal ini juga berarti bahwa Yesus, Allah Bapa dan Roh Kudus adalah satu di dalam pemahaman dan pengertian serta satu di dalam kasih. Oleh karena itu, Yesus menghendaki agar semua orang percaya menjadi satu sama seperti Dia, Allah Bapa dan Roh Kudus adalah satu. Jadi, selain Yesus memiliki natur sebagai manusia sejati, Ia juga memiliki natur sebagai Allah sejati, yang setara dengan Allah Bapa dan Roh Kudus.

\section{Kuasa}

Sejak manusia jatuh ke dalam dosa, manusia telah kehilangan kemuliaan Allah (Rom. 3: 23). Tidak ada seorang pun yang dapat memulihkan kemuliaan Allah dalam hidup manusia selain dari pada Allah sendiri. Pernyataan Yesus dalam Yohanes 17: 22 di mana Ia telah memberikan kemuliaan kepada semua orang percaya menunjukkan bahwa Ia adalah Allah yang berkuasa. Sebagaimana Allah Bapa berkuasa memberikan kemuliaan kepada Yesus, demikian juga Yesus berkuasa memberikan kemuliaan kepada semua orang percaya. Jadi, kuasa Yesus setara dengan kuasa Allah Bapa dan Roh Kudus.

Kesetaraan kuasa Yesus dan Allah Bapa dan Roh Kudus juga ditekankan oleh Matthew Henry dengan menuliskan:

The oneness that is between the Father and the Son, which is mentioned again and again, $v$. 11, 21-23. (1.) It is taken for granted that the Father and Son are one, one in nature and essence, equal in power and glory, one in mutual endearments. The Father loveth the Son, and the Son always pleased the Father. They are one in design, and one in operation. The intimacy of this oneness is expressed in these words, thou in me, and I in thee.

Jadi, selain membuktikan kesetaraan natur Yesus dengan Allah Bapa dan Roh Kudus, Yohanes 17: 22 juga membuktikan kesetaraan kuasa Yesus dengan Allah Bapa dan Roh Kudus.

\section{Mengajarkan Doktrin Allah Tritunggal}

Selain membuktikan kesetaraan Yesus, maka makna theologis yang lain dari Yohanes 17: 22 adalah mengajarkan doktrin Allah Tritunggal. Oleh karena itu, penulis 
akan memaparkan bahwa doktrin Tritunggal adalah doktrin yang alkitabiah dan Yesus adalah pribadi kedua Allah Tritunggal.

\section{Doktrin Allah Tritunggal Adalah Doktrin Yang Alkitabiah}

Pada pembahasan sebelumnya, penulis telah menuliskan bahwa pernyataan Yesus dalam Yohanes 17: 22 membuktikan kesetaraan Yesus dengan Allah Bapa dan Roh Kudus. Hal itu berarti Yesus adalah Allah. Yesus menyebut Dia dan Allah Bapa dengan istilah "Kita". Istilah "Kita" merupakan istilah yang pernah dipakai Allah untuk menyebut diri-Nya sendiri ketika hendak menciptakan manusia (Kej. 1: 26). Istilah "Kita" dalam Kejadian 1: 26 tersebut mengacu kepada Allah Tritunggal, yaitu Allah Bapa, Yesus Kristus, dan Roh Kudus (Kej. 1: 26 band. Mat. 28: 19). Jadi, Yohanes 17: 22 jelas mengajarkan bahwa Allah adalah Allah Tritunggal sehingga doktrin Tritunggal dalam kekristenan adalah doktrin yang alkitabiah.

\section{Yesus Adalah Pribadi Kedua Allah Tritunggal}

Dengan memahami istilah "Kita" yang dipakai oleh Yesus dalam Yohanes 17: 22, maka dapat dimengerti bahwa Yesus adalah pribadi kedua Allah Tritunggal. Di dalam Alkitab, secara khusus dalam Injil Matius, nama Yesus (Anak) disebut setelah nama Bapa (Mat. 28: 19) yang menunjukkan bahwa Yesus adalah pribadi kedua Allah Tritunggal. Hal ini tidak berarti bahwa Yesus lebih rendah kedudukan, natur dan kuasa-Nya dari pada Allah Bapa dan Roh Kudus, tetapi hanya menunjukkan urutan penyebutan pribadi Allah Tritunggal yang dijelaskan dalam Alkitab.

\section{Kesimpulan}

Injil Yohanes ditulis oleh rasul Yohanes, anak Zebedeus. Ia adalah seorang murid Tuhan Yesus. Ia menulis Injil Yohanes ketika ia berada di Efesus sekitar tahun 90-100 M. Injil Yohanes dialamatkan kepada orang-orang Yahudi yang tinggal di luar Palestina atau berdiaspora dengan tujuan untuk meyakinkan mereka bahwa Yesus adalah Mesias dan Anak Allah.

Yohanes 17: 22 adalah firman Allah yang menyatakan dua hal, yaitu membuktikan kesetaraan Yesus dengan Allah Bapa dan Roh Kudus dan mengajarkan doktrin Tritunggal. Yesus Kristus memiliki natur yang sama dengan Allah Bapa dan Roh Kudus atau sehakikat dengan Allah Bapa dan Roh Kudus. Ia juga memiliki kuasa yang sama atau setara dengan Allah Bapa dan Roh Kudus. Jadi, Yesus adalah Allah. Istilah "Kita" dalam Yohanes 17: 22 mengacu kepada Yesus, Allah Bapa dan Roh Kudus. Jika dipahami dari keseluruhan ajaran Alkitab, maka istilah "Kita" mengacu kepada Allah Tritunggal. Oleh karena itu, Yohanes 17: 22 mengajarkan bahwa doktrin Allah Tritunggal adalah doktrin yang alkitabiah dan Yesus Kristus adalah pribadi kedua Allah Tritunggal. 


\section{Kepustakaan}

Arndt, William F. F. Wilbur Gingrich (Rev.),

1979 A Greek-English Lexicon of The New Testament and Other Early

Christian Literature, Chichago: The University of Chichago Press,

Balz, Horst Gerhard Schneider (eds.),

1990 Exegetical Dictionary of the New Testament, Volume 1, Grands

Rapids, Michigan: William B. Eerdmans Publishing Company,

Carson, D. A.

1991 The Gospel According to John, Grand Rapids, Michigan: William

Daun, Paulus

B. Eerdmans Publishing Company,

1994 Bidat Kristen Dari Masa Ke Masa, Manado: Yayasan "Daun Family",

Erickson, Millard J.

2003 Teologi Kristen, Volume Dua, Malang: Gandum Mas,

Hendriksen, William

1981 New Testament Commentary: The Gospel of John, Edinburgh: The Banner of Truth Trust,

Henry, Matthew

1982 Matthew Henry's Commentary, Grand Rapids, Michigan: Zondervan Publishing House,

Jeffrey, David Lyle (ed.)

1992 A Dictionary of Biblical Tradition in English Literature, Grand Rapids, Michigan: William B. Eerdmans Publishing Company,

Keener, Craig S.

1993 The IVP Bible Background Commentary New Testament, Downers

Groove, Illinois: InterVarsity Press,

Lumintang, Stevri Indra

2010 Keunikan Theologia Kristen di Tengah Kepalsuan, Batu:

Departemen Literatur, PPII,

Morgan, G. Campbell

1947 The Gospel According to John, London, Edinburgh: Marshal, Morgan and Scott, LTD.,

Morris, Leon

1988 Expository Reflections on the Gospel of John, Grand Rapids, Michigan,

R. C. Sproul,

2002

Kebenaran-kebenaran Dasar Iman Kristen, Malang: Departemen Literatur SAAT,

Ryrie, Charles C.

1991 Teologi Dasar 1, Yogyakarta: ANDI,

Strong, James

1982

Thiessen, Henry C. 1992

Strong's Exhaustive Concordance, Milford: Mott Media,

Teologi Sistematika, Malang: Gandum Mas,

Til, Cornelius Van 
Pengantar Theologi Sistematik: Prolegomena dan Doktrin Wahyu, Alkitab, dan Allah, Surabaya: Momentum,

Tong, Stephen

2012

Vine, W. E.

1940
Allah Tritunggal, Surabaya: Momentum,

Expository Dictionary of New Testament Words, Grand Rapids, Michigan: Zondervan Publisihing House, 